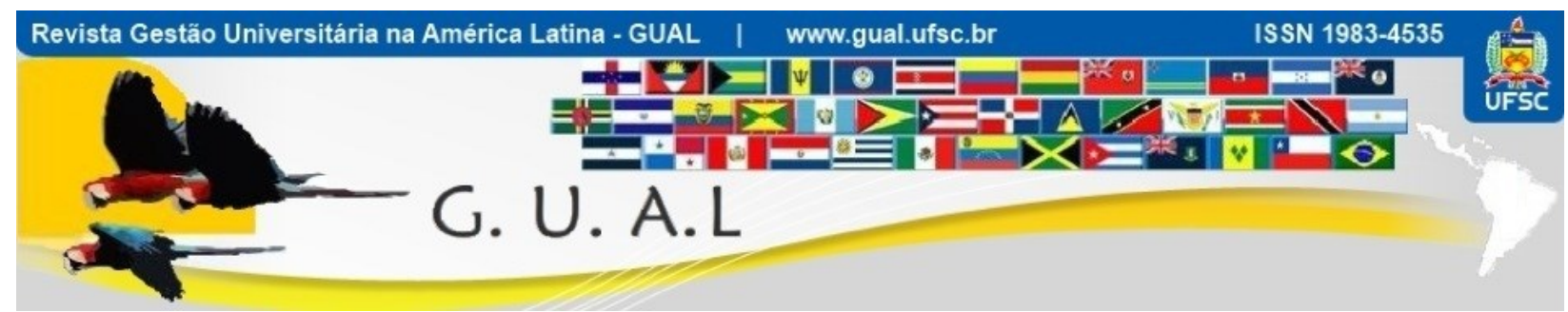

DOI: https://doi.org/10.5007/1983-4535.2021.e79255

\title{
ENSINO REMOTO NA EDUCAÇÃO SUPERIOR EM TEMPOS DE DISTANCIAMENTO SOCIAL: UMA INVESTIGAÇÃO NAS INSTITUIÇÕES DE ENSINO SUPERIOR PRIVADA DE UM GRUPO EDUCACIONAL DO BRASIL
}

\section{REMOTE TEACHING IN HIGHER EDUCATION IN TIMES OF SOCIAL DISTANCE: AN INVESTIGATION IN PRIVATE HIGHER EDUCATION INSTITUTIONS OF AN EDUCATIONAL GROUP IN BRAZIL}

Henrique César Melo Ribeiro, Doutor https://orcid.org/0000-0002-0704-1812 hcmribeiro@hotmail.com Universidade Federal do Delta do Parnaíba | Campus Ministro Reis Velloso Parnaíba | Piauí | Brasil

Rosany Corrêa, Doutora https://orcid.org/0000-0002-2599-2742 rosanycorrea@hotmail.com Faculdade Maurício de Nassau | Unidade de Parnaíba Parnaíba | Piauí | Brasil

Recebido em 29/janeiro/2021

Aprovado em 16/junho/2021

Publicado em 01/setembro/2021

Sistema de Avaliação: Double Blind Review

Esta obra está sob uma Licença Creative Commons Atribuição-Uso. 


\title{
RESUMO
}

O objetivo deste estudo foi investigar a influência do ensino remoto na educação superior nas Instituições de Ensino Superior Privada de um Grupo Educacional do Brasil em tempos de distanciamento social. Metodologicamente a mencionada pesquisa enfocou uma abordagem quantitativa. $\mathrm{O}$ instrumento de coleta foi um questionário fechado enviado para os docentes e discentes das Instituições de Ensino Superior Privadas de um Grupo Educacional do Brasil localizadas no Piauí. Apesar dos impactos da pandemia, que ocasionaram o isolamento social, os resultados evidenciam que as IES ligadas ao grupo educacional objeto do estudo, não tiveram interrupção das aulas, que ocorreram de forma remota. Os principais resultados evidenciam que as instituições respondentes, possuem ferramentas tecnológicas que facilitam o desenvolvimento das aulas remotas, usam metodologias ativas e os docentes por estarem familiarizados a modalidade $\mathrm{EaD}$ não tiveram muitas dificuldades em migrar para o sistema remoto, e muitos dos respondentes se sentiram desafiados em participar de atividades na modalidade ensino remoto. Concluiu-se que as instituições estudadas tiveram menos impactos no processo de mudança do ensino presencial para o remoto, na visão dos alunos e professores respondentes.

Palavras-chave: Ensino Remoto. Educação Superior. Instituições de Ensino Superior Privadas. Distanciamento Social.

\begin{abstract}
The aim of this study was to investigate the influence of remote education on higher education in Private Higher Education Institutions of an Educational Group in Brazil in times of social distance. Methodologically, the aforementioned research focused on a quantitative approach. The collection instrument was a closed questionnaire sent to teachers and students from Private Higher Education Institutions of an Educational Group in Brazil located in Piauí. Despite the impacts of the pandemic, which caused social isolation, the results show that the HEIs linked to the educational group object of the study, had no interruption of classes, which occurred remotely. The main results show that the respondent institutions have technological tools that facilitate the development of remote classes, use active methodologies and the teachers because they are familiar with the distance learning modality did not have many difficulties in migrating to the remote system, and many of the respondents felt challenged to participate in remote teaching activities. It was concluded that the studied institutions had less impacts in the process of changing from on-site to remote education, in the view of the respondent students and teachers.
\end{abstract}

Keywords: Remote Education. College Education. Private Higher Education Institutions. Social Distancing. 


\section{INTRODUÇÃO}

O Ensino a Distância $(\mathrm{EaD})$ está previsto na política educacional de educação superior no Brasil (GONÇALVES; SILVA, 2020) alicerçada pelas Tecnologias da Informação e Comunicação (TICs) (VASCONCELOS; OLIVEIRA, 2017; YAMANAKA; CAPPELLOZZA, 2018), cujas ferramentas passam a alargar e dinamizar todo o processo de ensino-aprendizagem na educação superior (CASSUNDÉ; MENDONÇA; BARBOSA, 2017; UNESCO, 2020). Posto isto, entende-se que na medida em que as potencialidades do ensino superior são viabilizadas com apoio das TIC, inúmeras atividades têm sido permitidas com o $\mathrm{EaD}$, influenciando, sobremaneira, tanto as Instituições de Ensino Superior (IES) quanto a docência (CASSUNDÉ; MENDONÇA; BARBOSA, 2017). Reitera-se que de acordo com a Portaria de n. 2.117, de 06 de dezembro de 2019, as IES podem oferecer o EaD contendo 20\% da carga horária do curso, podendo esta, em casos especiais se expandir para 40\% (SOUZA et al., 2020).

Ademais, com o aparecimento da pandemia do vírus causador da Síndrome Respiratória Aguda Grave do coronavírus 2 (Severe Acute Respiratory Syndrome coronavirus 2 - Sars-CoV-2) designado COVID-19 (SOUZA, 2020), e, concomitantemente o realce ao isolamento social, que é parte preponderante da medida de saúde pública para controle desta pandemia (KUWAHARA; KURODA; FUKUDA, 2020), robusteceu e alargou por completo a realidade do ensino à distância no mundo (WATTS, 2016; JOYE; MOREIRA; ROCHA 2020; MANCHEIN et al., 2020) e, consequentemente no Brasil (CAMACHO et al., 2020). Isto posto, ressalva-se que, em consideração as medidas de isolamento social o Ministério da Educação estabeleceu a Portaria $n^{\circ}$ 343, de 17 de Março de 2020 que dispõe sobre a substituição das aulas presenciais por aulas em meios digitais enquanto durar a situação do COVID-19 (BARBOSA; VIEGAS; BATISTA, 2020; CAMACHO et al., 2020).

Posto isto, entende-se e constata-se que o isolamento social, em decorrência do COVID-19, afetou organizações, como as próprias Instituições de Ensino Superior (IES), que decidiram transformar seus padrões de trabalho, no que concerne a oferta dos serviços de educação no ensino superior (MARKOWSKA-MANISTA; ZAKRZEWSKA-OLĘDZKA, 2020; SPALDING et.al., 2020) de presencial para digital (CRAWFORD et al., 2020; WARGO; D’ALENE, 2020). E as atividades de educação a distância, as aulas on-line e remotas são 
exemplos de estratégias (SILVA et al., 2020) que podem e ou estão sendo implementadas e praticadas por IES no Brasil.

Diante disso, enfoca-se que cursos de graduação, que é o foco deste estudo, podem e devem usar metodologias remotas para a continuidade no ano letivo atual, propiciando com isso ao discente, a sensação de imersão, de estar na sala de aula, da navegação e interação em um ambiente virtual, sendo que o docente, respeitando os princípios educacionais e a abordagem pedagógica que ele acredita, não transformará esse momento em uma simples educação a distância (BEZERRA, 2020).

Fernandes, Henn e Kist (2020) traçaram um panorama histórico geral das diferentes formas de desenvolvimento do ensino a distância no Brasil. Observaram que os potenciais dos ambientes virtuais de formação ainda estão em processo de construção e reflexão, no que tange as suas contribuições com os cursos a distância e quanto a difusão de pesquisas científicas que envolvem tal temática na literatura científica nacional. Ainda em relação aos autores Fernandes, Henn e Kist (2020) estes sugerem a necessidade de realização de estudos que enfoquem os docentes e discentes e suas respectivas compreensões no que concerne o ensino à distância na educação superior.

Diante do exposto, enfatiza-se a questão de pesquisa que norteará este estudo: Qual a influência do ensino remoto na educação superior nas Instituições de Ensino Superior Privada de um Grupo Educacional do Brasil em tempos de distanciamento social? E para ajudar a responder a referida pergunta, este estudo traz a baila o objetivo que é: Investigar a influência do ensino remoto na educação superior nas Instituições de Ensino Superior Privada de um Grupo Educacional do Brasil em tempos de distanciamento social.

Justifica-se estudar o EaD por constatar como este se desenvolveu no âmbito mundial, sobretudo, neste momento de pandemia e, consequente distanciamento social (CAMACHO et al., 2020; GUSSO et.al., 2020), tornado assim importante estuda-lo para melhor entende-lo no que pertence a sua performance nos cursos de graduação das IESsP, contribuindo para otimizar sua compreensão e criar reflexões de seu desempenho nos cursos de graduação, criando assim possibilidades de alavancar pesquisas análogas a essa, ampliando as informações e conhecimentos sobre o ensino remoto na educação superior do Brasil.

Outra contribuição desta pesquisa é observar e, a posteriori evidenciar os ambientes/plataformas/simulacros virtuais, digitais, online, criadas e, concomitantemente usadas pelas IESsP investigadas, alicerçada pelas Tecnologias de Informação e Comunicação, 
para assim melhor entender e compreender como estas IESsP conseguiram performar em seus respectivos cursos o ensino remoto na educação superior de cada uma, à luz de seus docentes e discentes. Isto posto, reforça-se assim, a necessidade do desenvolvimento de novas tecnologias que permitam conduzir o processo do ensino remoto na educação superior de maneira ética e segura (MARASCA et al., 2020).

Este estudo está subdivido em cinco seções. A primeira enfoca a Introdução; Em seguida é enfatizado o Referencial teórico; Na terceira seção é abordado os Procedimentos metodológicos; A Análise e discussão dos resultados é realçada na seção quatro; E, as Considerações finais é evidenciada na seção cinco.

\section{DISTANCIAMENTO SOCIAL, EDUCAÇÃO SUPERIOR E O ENSINO REMOTO}

Medicamentos para o tratamento efetivo ou vacinas para impedir a infeção pelo SARS-CoV-2 não estão disponíveis até o momento. Diante disso, aconselha-se distanciamento social, etiqueta respiratória e higienização das mãos como medidas de combate ao COVID-19 (GARCIA FILHO; VIEIRA; SILVA, 2020). O distanciamento social foi planejado como uma medida, não farmacológica, preventiva para controlar a disseminação extensiva do COVID-19 (considerada uma pandemia no mundo e, consequentemente no Brasil), ou seja, o isolamento social é preponderante para mitigar a curva epidêmica desta pandemia (VALENTI et al., 2020).

Na pesquisa de Manchein et al. (2020) os autores analisaram o crescimento do número acumulado de casos confirmados de infecção pelo COVID-19 em países dos continentes Ásia, Europa, América do Norte e América do Sul. Tal estudo concluiu que o isolamento social das pessoas é a principal estratégia, até o momento, para se conseguir achatar a curva de infecção do vírus e mortes (MANCHEIN et al., 2020). E aqui no Brasil, o tema distanciamento social foi o de maior destaque entre as medidas de contenção (GARCIA FILHO; VIEIRA; SILVA, 2020).

Os autores Volpatto et al. (2020) discutiram algumas medidas de relaxamento do distanciamento social e seus impactos no sentido epidemiológico, com o objetivo de avaliar os efeitos nas projeções da epidemia da COVID-19 no Brasil e, em particular, no estado do Rio de Janeiro. Concluíram que no panorama atual, em que não é possível aferir o controle epidemiológico, as medidas de relaxamento do distanciamento social estudadas não são recomendadas. 
No Brasil, no que tange a educação superior, foram tomadas medidas de isolamento social para prevenir e mitigar a propagação do COVID-19. Com isso, foram determinadas pelas autoridades competentes no Brasil o fechamento de IES que tiveram, portanto, que suspender suas aulas e atividades presenciais dando como viabilidade e continuidade da ensino-aprendizagem por meio do ensino à distância. Entretanto, é salutar enfatizar que, tanto para os docentes, e, sobretudo para os discentes que não dispõem de todos os recursos para acesso aos conteúdos ministrados na modalidade $\mathrm{EaD}$ é preponderante a visibilidade das necessidades destes em termos de preparo para lidar com as TICs no ensino remoto na educação superior (VASCONCELOS; OLIVEIRA, 2017; CAMACHO et al., 2020; SILVEIRA et al., 2020; UNESCO, 2021).

A educação superior é estratégica para qualquer país, por ser massificada e diversificada, e sua relevância é destacada no âmbito cultural, econômico, político e social, sendo, portanto, considerada fonte de pesquisa importante por meio de diferentes perspectivas, sobretudo nas IESsP, a qual encontram-se em uma crescente no segmento educacional no Brasil (MACIEL; CUNHA JÚNIOR; LIMA, 2019; PIMENTA; ROSSO; SOUSA, 2019; SANTOS et al., 2020). E a EaD está em uma trajetória ascendente na educação superior, sobretudo nos tempos de hoje em decorrência da pandemia (CASTIONI; MELO, 2020; FERNANDES; HENN; KIST, 2020; GUSSO et.al., 2020), especialmente nas IESsP.

Brito, Ferasso e Estrela (2020) apresentaram como a EaD se tornou um objetivo nacional do governo moçambicano para assegurar o acesso à educação superior a um número cada vez maior de cidadãos e de melhorar a qualidade dos serviços prestados no ensinoaprendizagem. Concluíram que o enfoque sistêmico de concepção, produção e implementação de programas de ensino à distância estão garantindo a realização do objetivo nacional do governo de Moçambique.

Verifica-se que o trabalho remoto pode vir de várias formas, cada um com seu próprio benefício e desafios. E os resultados das atividades remotas dependem diretamente e substancialmente das tecnologias e, simultaneamente dos métodos de adoção e implementação destes sistemas remotos (HE et al., 2020). Diante disso, observa-se que as restrições impostas pelo distanciamento social decorrente do COVID-19 exigiram adaptações de professores a uma nova realidade de trabalho que privilegia atividades remotas 
(MARASCA et al., 2020), que são mecanismos usados na educação a distância nos ambientes virtuais de aprendizagem, bem como de formação.

Pode-se conceber com isso que, o trabalho remoto acompanha a própria evolução dos ambientes digitais/virtuais, além de seus recursos utilizados. Posto isto, os potenciais destes ambientes são ainda inexplorados, visto que, estes estão ainda em processo de construção e reflexão, tanto em relação as suas atuações dentro dos cursos de educação a distância, quanto nas pesquisas científicas que envolvem essa temática (FERNANDES; HENN; KIST, 2020). Diante desse panorama, esboça-se que para o sucesso das atividades remotas no ambiente da educação superior é necessário, além dos TIC, de estratégias de ensino-aprendizagem, corpo docente e discentes que aprendam rapidamente a alterar seus fluxos de trabalho anteriores, para os que estão em voga nos dias de hoje em virtude das mudanças impostas pelo distanciamento social (HE et al., 2020).

Enfatiza que algumas estratégias de ensino como: palestras, estudo de caso, debates, discussões, aprendizado experimental, sessões de brainstorming, jogos podem ser usados online para facilitar práticas eficazes e eficientes de ensino-aprendizagem (DHAWAN, 2020). Representando assim uma transição das normas e práticas tradicionais, imperando e impondo as IES desafios associados à adoção, implementação e práticas de estratégias em EaD na educação superior buscando com isso resultados positivos e, consequentemente satisfação dos atores envolvidos no processo de ensino-aprendizagem no ensino superior. Uma vez que todos esses agentes (docentes, discentes, diretores, coordenadores, colaboradores dentre outros) aceitaram e adotaram as atividades e as práticas do trabalho remoto no EaD (HE et al., 2020). Malan (2020) afirma que o envolvimento dos discentes é crucial para o aprendizado, notadamente na prática on-line.

Devido ao COVID-19, cursos inteiros precisaram ser convertidos em ensinoaprendizado on-line (MALAN, 2020). Diante disso, Malan (2020) discutiu um módulo contábil de um nível totalmente on-line em que a colaboração foi propositalmente integrada usando uma estrutura de engajamento. Os resultados indicaram que a incorporação de cinco formas de envolvimento no módulo foi recebida positivamente pelos discentes e resultou em mais alunos concluindo o módulo com êxito. As reflexões dos discentes mostraram que o módulo era cognitivo, que a preferência pessoal guiaria o engajamento social e que trabalhar em cooperação sempre será um desafio. Entende-se com isso ser preponderante, para que o ensino remoto consiga êxito na educação superior, fornecimento de técnicas e tecnologias 
adequadas e de apoio satisfatório ao ensino-aprendizagem tanto aos docentes quanto aos discentes (DHAWAN, 2020).

No estudo de Silveira et al. (2020) os autores apresentaram alternativas tecnológicas que podem ser adotadas para apoiar o ensino remoto durante o período de isolamento social, em virtude do COVID-19. Sendo assim os autores evidenciam as seguintes alternativas: sala de aula invertida, a aprendizagem baseada em problemas, aprendizado baseado em projetos, Ambientes Virtuais de Aprendizagem (AVA), simuladores, laboratórios virtuais, Moodle.

Barbosa, Viegas e Batista (2020) analisaram e apresentaram os impactos identificados e relatados pelos profissionais de educação do ensino superior, do município do Rio de Janeiro e Região Metropolitana, mediante isolamento social, sobre suas experiências do novo modelo de aula proposto pelas instituições, denominado como aula remota. Concluíram que ser eficiente, o modelo de aulas remotas, pois houve uma boa realização das tarefas e atividades conforme o planejado. Contudo, não eficaz, a considerar que não houve uma totalidade de discentes com acesso ao ensino/aprendizagem, fator que compromete a qualidade da prestação de serviço das IES públicas e privadas.

Posto isto, também é importante informar que os softwares apresentados e adotados nas IES para o modelo de aula são adaptados. Com isso, estas ferramentas são meios de interação que atendem a modelos da IES, com objetivo de conectar os docentes, discentes e colaboradores, e melhorar a interação entre eles, fornecendo uma alternativa de comunicações, e até mesmo substituição do uso de e-mail. Ao olhar dos docentes, muito bem adaptados, porque permite ao discente, um contato com a realidade do AVA (BARBOSA; VIEGAS; BATISTA, 2020).

Em contrapartida observa-se no estudo de Martins e Ribeiro (2019) que é extremamente importante saber o nível de engajamento que os discentes têm no âmbito do ensino superior à distância. Posto isto, os autores propuseram um modelo para que se consiga avaliar tal nível de comprometimento, aplicado em diferentes cursos, assim como em Universidades, Centros Universitário ou Faculdades, independente do número de alunos. E estas informações geradas por meio deste modelo são de suma importância para melhor entender e compreender a atuação dos diferentes atores envolvidos no processo de ensino remoto na educação superior, sobretudo os discentes, contribuindo e influenciando na potencialização e robustez da qualidade de cursos a distância (MARTINS; RIBEIRO, 2019; JOYE; MOREIRA; ROCHA 2020). 
E cabe ainda considerar, também, que nesse processo ensino-aprendizado, o docente, pode ser acometido por uma outra problemática, talvez desconhecida, que seja, a frustação do não conhecimento e domínio integral das TICs, ampliando sua carga horária de trabalho em busca dessa competência e habilidade. Cabendo, ainda, mais atenção, pois tudo isso, passando pelo processo do COVID-19, de total distanciamento social, requer de equilíbrio emocional e boas práticas para manter, também, uma saúde física, mental, econômica e financeira. Em suma, considera-se o fato de que, para se obter uma boa relação entre tecnologia e o docente, é preciso que haja o mínimo necessário de treinamento, mesmo àqueles docentes que de algum modo já possuíam habilidades com as TICs (BARBOSA; VIEGAS; BATISTA, 2020).

\section{PROCEDIMENTOS METODOLÓGICOS}

O objetivo deste estudo foi investigar a influência do ensino remoto na educação superior nas Instituições de Ensino Superior Privada de um Grupo Educacional do Brasil em tempos de distanciamento social. Diante disso, a referida pesquisa será do tipo exploraria, em decorrência desta ser propicia para ajudar a responder questões de pesquisa com pouco aprofundamento do conhecimento científico (GOUVÊA; ONUSIC; MANTOVANI, 2016).

\subsection{PROCEDIMENTOS DE COLETA DE DADOS}

Por ser um estudo com predomínio quantitativo optou-se por adotar questionário (REYES JÚNIOR et al., 2018). Cada pergunta do questionário (Quadro 1) foi avaliado numa escala tipo Likert de cinco categorias, de 1-Nenhuma Correspondência (NC), 2-Pouca Correspondência (PC), 3-Moderada Correspondência (MC), 4-Muita Correspondência (MUC), 5-Total Correspondência (TC) (RIBEIRO et al., 2019). É importante evidenciar que para cada afirmação do questionário, foi usada as suas devidas e respectivas fontes de pesquisa que tornaram possível a construção destas afirmações, embasando-as e norteando-as concomitantemente. $\mathrm{O}$ citado questionário está dividido em duas seções. A primeira enfoca a Identificação dos Respondentes (PÉRICO; GONÇALVES, 2018); e a segunda parte do questionário enfatiza as afirmativas que alicerçam e norteiam a questão e o objetivo central desta pesquisa (RIBEIRO, 2014). 
Quadro 1: Questionário

\begin{tabular}{|c|c|c|c|}
\hline \multicolumn{4}{|c|}{ Identificação do Respondentes } \\
\hline Sexo & \multicolumn{3}{|c|}{ Masculino ( ); Feminino ( ) } \\
\hline Identificação & \multicolumn{3}{|c|}{ Docente ( ); Discente ( ) } \\
\hline Faixa etária & & \multicolumn{2}{|c|}{18 a 25 anos ( ); 26 a 35 anos ( ); 36 a 45 anos ( ); 46 anos ou mais ( ) } \\
\hline \multicolumn{2}{|c|}{$\begin{array}{l}\text { A IES a qual tenho } \\
\text { vínculo fica na Capital } \\
\text { do Piauí }\end{array}$} & \multicolumn{2}{|l|}{ Sim ( ); Não ( ) } \\
\hline \multicolumn{4}{|c|}{ Afirmativas sobre a influência do ensino remoto na educação superior } \\
\hline \multicolumn{2}{|c|}{$\begin{array}{l}\text { Questão de pesquisa e } \\
\text { Objetivo da pesquisa }\end{array}$} & Afirmativas & Fonte \\
\hline \multirow{15}{*}{ 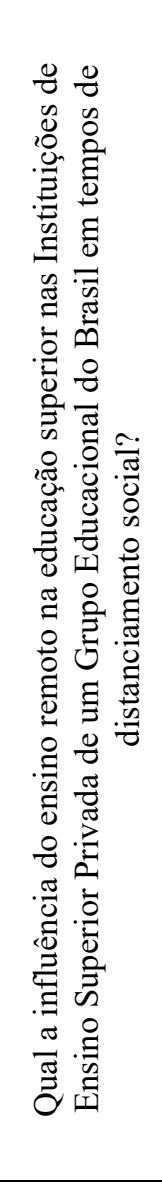 } & \multirow{15}{*}{ 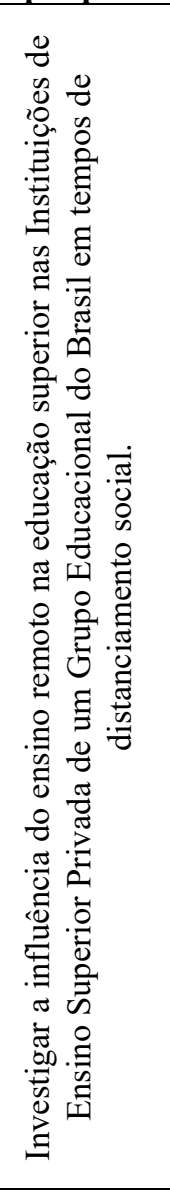 } & $\begin{array}{l}\text { 1. O isolamento social, em decorrência da pandemia do } \\
\text { COVID-19, interrompeu minhas práticas acadêmicas. }\end{array}$ & \multirow{15}{*}{ 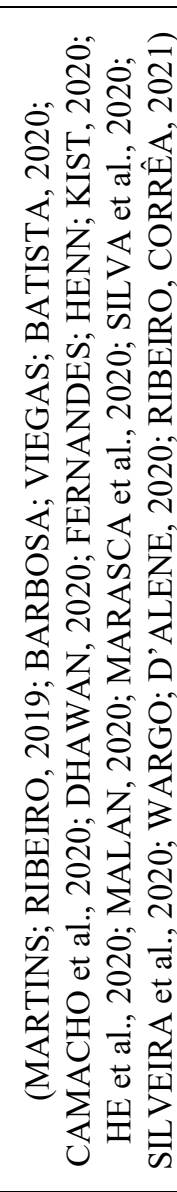 } \\
\hline & & $\begin{array}{l}\text { 2. Participar da implantação de atividades na modalidade } \\
\text { ensino remoto, foi um grande desafio para mim. }\end{array}$ & \\
\hline & & 3. Tinha experiência com o EaD. & \\
\hline & & $\begin{array}{l}\text { 4. A instituição dispõe de ferramentas como sala invertida, } \\
\text { sala de metodologias ativas, lousa digital ou outras. }\end{array}$ & \\
\hline & & $\begin{array}{l}\text { 5. Foi difícil implementar a modalidade ensino remoto, por } \\
\text { resistência dos docentes. }\end{array}$ & \\
\hline & & $\begin{array}{l}\text { 6. Foi difícil implementar a modalidade ensino remoto, por } \\
\text { resistência dos discentes. }\end{array}$ & \\
\hline & & $\begin{array}{l}\text { 7. A parte mais difícil do EaD foram as provas em forma } \\
\text { remota. }\end{array}$ & \\
\hline & & $\begin{array}{l}\text { 8. O sistema implantando de aulas remotas, possibilitou a } \\
\text { inclusão do discente na sala de aula de forma on-line. }\end{array}$ & \\
\hline & & $\begin{array}{l}\text { 9. O processo didático pedagógico do ensino remoto ocorre } \\
\text { melhor do que o ensino presencial. }\end{array}$ & \\
\hline & & $\begin{array}{l}\text { 10. Senti um grande impacto de sair do modelo presencial } \\
\text { para o EaD enfocando o ensino remoto. }\end{array}$ & \\
\hline & & $\begin{array}{l}\text { 11. Como tenho domínio de tecnologias a mudança, para o } \\
\text { ensino remoto, foi muito confortável. }\end{array}$ & \\
\hline & & $\begin{array}{l}\text { 12. Minha adaptação ao ensino remoto foi sentida com maior } \\
\text { intensidade pela falta de alguns encontros presenciais. }\end{array}$ & \\
\hline & & 13. Me sinto inseguro diante do ensino remoto. & \\
\hline & & $\begin{array}{l}\text { 14. Minha maior dificuldade ao EaD, e consequentemente no } \\
\text { ensino remoto, se deu pela falta de uma internet segura. }\end{array}$ & \\
\hline & & $\begin{array}{l}\text { 15. Nesse período a IES dispôs de um time de TICs que } \\
\text { permitiu alcançar soluções frente as demandas da comunidade } \\
\text { acadêmica e, consequentemente ao ensino remoto. }\end{array}$ & \\
\hline
\end{tabular}

Fonte: Elaborado pelos autores, adaptado de Ribeiro (2014).

O referido questionário foi enviado para o universo de 328 docentes e 12050 discentes das 3 (três) Instituições de Ensino Superior Privadas de um Grupo Educacional do Brasil (IESsPGEB) localizadas no Estado do Piauí. A IESsP(UA) contém 90 docentes e 3500 discentes; A IESsP(UP) têm 121 professores e 4200 aluna(o)s; e a IESsP(UT) opera com 117 professores e 4350 discentes. Justifica-se estudar o citado Grupo Educacional e suas 3 (três) 
IES em decorrência deste ser um dos maiores Grupos Educacionais do Brasil, bem como o aceite por parte do citado Grupo em participar do referido estudo.

\section{ANÁLISE E DISCUSSÃO DOS RESULTADOS}

Essa seção apresenta a análise e discussão dos resultados deste estudo, ficando evidente nos itens abordados através das respostas dos respondentes e entremeado por outros estudos, como esse assunto mobiliza e induz um aprofundamento da importância das práticas didáticos pedagógicas pela visão do docente como do discente.

Os impactos da pandemia efetivada pelo novo Coronavírus - Covid-19 na educação têm sido grandiosos, o isolamento social impôs uma série de medidas preventivas para evitar a propagação do vírus. E as escolas por envolverem um grande número de pessoas de forma sistêmica tiveram que se adaptar as normativas que orientaram a continuidade da oferta do ensino. Sendo que, muitas instituições de diversos níveis de ensino, paralisaram suas atividades escolares, enquanto outras, mudaram suas atividades para o ensino remoto. Segundo dados levantados pela Organização das Nações Unidas para a Educação, a Ciência e a Cultura (UNESCO), mais de 70\% da população estudantil do mundo, estão sendo afetados em todo o mundo, o fechamento das escolas acarreta altos custos sociais e econômicos para as pessoas nas diferentes comunidades (UNESCO, 2021)

As estratégias adotadas para dar continuidade das instituições as aulas, acabaram por induzirem as IES de uma forma quase instantânea para não interromper o ano letivo. Estratégias inovadoras com foco nas tecnológicas vêm afetando a tomada de decisão nas instituições o que acaba afetando toda a comunidade acadêmica. Tecnologias como inteligência artificial, blockchain, internet das coisas e computação quântica fazem parte do ambiente das organizações (RIBEIRO, CORRÊA, 2021), e induzem a inclusão de todos nesse processo de inovação tecnológica e estimulando as universidades a se tornarem pontos de referência no que tange a práticas pedagógicas.

Do ensino básico ao superior, o isolamento social já traz grandes consequências educacionais, deixando professores, alunos e profissionais da educação em meio às incertezas e questionamentos sobre o futuro e o desenvolvimento do setor educacional. Embora a pandemia tenha causado um impacto totalmente abrupto sobre as IES, na maioria dos casos, sem outro plano de contingência que não seja tentar dar continuidade às aulas à distância, é 
importante começar a traçar as linhas fundamentais para a saída desta crise, garantindo os mais altos graus possíveis de inclusão e equidade (UNESCO, 2020).

\subsection{PERFIL DOS RESPONDENTES}

A Tabela 1 evidencia o perfil dos respondentes.

Tabela 1 Perfil dos respondentes

\begin{tabular}{|c|c|c|}
\hline Gênero & Feminino $=53 \%$ & Masculino $=47 \%$ \\
\hline Identificação & Discente $=18 \%$ & Docente $=82 \%$ \\
\hline Faixa etária & \multicolumn{2}{|c|}{$\begin{array}{c}18 \text { a } 25 \text { anos }=12 \% ; 26 \text { a } 35 \text { anos }=26 \% ; 36 \text { a } 45 \text { anos }=34 \% \text {; Maior ou igual a } \\
46 \text { anos }=28 \%\end{array}$} \\
\hline $\begin{array}{l}\text { A IES a qual tem vínculo } \\
\text { fica na capital do Piauí? }\end{array}$ & $\operatorname{Sim}=39 \%$ & Não $=61 \%$ \\
\hline
\end{tabular}

Fonte: Dados da pesquisa.

Observou-se que os docentes foram a grande maioria com $82 \%$ deles, quanto ao gênero o resultado mostra praticamente a mesma entre o feminino e masculino, e uma grande maioria com idade abaixo de 45 anos, correspondendo a $72 \%$ do total. $61 \%$ dos respondentes residem fora da capital do Estado do Piauí.

\subsection{A INFLUÊNCIA DO ENSINO REMOTO NA EDUCAÇÃO SUPERIOR}

A Tabela 2 contempla a influência do ensino remoto na educação superior à luz das IESs investigadas e sob a óptica das respostas dos docentes e discentes.

A Tabela 2 apresenta de forma condensada as afirmativas que foram apresentadas aos respondentes com intuído de resgatar as percepções deles quanto a 15 itens, que subsidiaram o desenvolvimento do estudo. De forma contundente discentes e docentes afirmam que as atividades acadêmicas não foram interrompidas em decorrência do isolamento social, o que subsidia todas as afirmativas elencadas.

A UNESCO (2020), afirma que os estudantes, que tiveram a sorte de ter garantida a continuidade das atividades, também tiveram que fazer um esforço para se adaptar ao que, para muitos deles, são novas formas de ensino e aprendizagem, o que pode ser contatado no estudo uma vez que os alunos tiveram mais dificuldade em se adaptar $64 \%$ deles, o que configura algo surpreendente uma vez que os alunos tem mais acesso com novas tecnologia, através de celulares e computadores. 


\section{ENSINO REMOTO NA EDUCAÇÃO SUPERIOR EM TEMPOS DE DISTANCIAMENTO SOCIAL: UMA INVESTIGAÇÃO NAS INSTITUIÇÕES DE ENSINO SUPERIOR PRIVADA DE UM GRUPO EDUCACIONAL DO BRASIL DOI: https://doi.org/10.5007/1983-4535.2021.e79255}

Tabela 2 A influência do ensino remoto na educação superior

\begin{tabular}{|c|c|c|c|c|c|}
\hline Afirmativas & NC & PC & MC & MUC & TC \\
\hline $\begin{array}{l}\text { O isolamento social, em decorrência da pandemia do COVID-19, } \\
\text { interrompeu minhas práticas acadêmicas }\end{array}$ & $43 \%$ & $25 \%$ & $23 \%$ & $8 \%$ & $1 \%$ \\
\hline $\begin{array}{l}\text { Participar da implantação de atividades na modalidade ensino remoto, foi } \\
\text { um grande desafio para mim }\end{array}$ & $8 \%$ & $14 \%$ & $29 \%$ & $34 \%$ & $15 \%$ \\
\hline Tinha experiência com o EaD & $12 \%$ & $23 \%$ & $38 \%$ & $8 \%$ & $19 \%$ \\
\hline $\begin{array}{l}\text { A instituição dispõe de ferramentas como sala invertida, sala de } \\
\text { metodologias ativas, lousa digital ou outras }\end{array}$ & $1 \%$ & $17 \%$ & $19 \%$ & $41 \%$ & $22 \%$ \\
\hline $\begin{array}{l}\text { Foi difícil implementar a modalidade ensino remoto, por resistência dos } \\
\text { docentes }\end{array}$ & $46 \%$ & $35 \%$ & $15 \%$ & $1 \%$ & $3 \%$ \\
\hline $\begin{array}{l}\text { Foi difícil implementar a modalidade ensino remoto, por resistência dos } \\
\text { discentes }\end{array}$ & $10 \%$ & $26 \%$ & $42 \%$ & $15 \%$ & $7 \%$ \\
\hline A parte mais difícil do EaD foram as provas em forma remota & $10 \%$ & $32 \%$ & $38 \%$ & $8 \%$ & $12 \%$ \\
\hline $\begin{array}{l}\text { O sistema implantando de aulas remotas, possibilitou a inclusão do } \\
\text { discente na sala de aula de forma on-line }\end{array}$ & $5 \%$ & $5 \%$ & $43 \%$ & $26 \%$ & $21 \%$ \\
\hline $\begin{array}{l}\text { O processo didático pedagógico do ensino remoto ocorre melhor do que o } \\
\text { ensino presencial }\end{array}$ & $25 \%$ & $28 \%$ & $41 \%$ & $3 \%$ & $3 \%$ \\
\hline $\begin{array}{l}\text { Senti um grande impacto de sair do modelo presencial para o EaD } \\
\text { enfocando o ensino remoto }\end{array}$ & $10 \%$ & $17 \%$ & $39 \%$ & $24 \%$ & $10 \%$ \\
\hline $\begin{array}{l}\text { Como tenho domínio de tecnologias a mudança, para o ensino remoto, foi } \\
\text { muito confortável }\end{array}$ & $8 \%$ & $10 \%$ & $49 \%$ & $18 \%$ & $15 \%$ \\
\hline $\begin{array}{l}\text { Minha adaptação ao ensino remoto foi sentida com maior intensidade pela } \\
\text { falta de alguns encontros presenciais }\end{array}$ & $7 \%$ & $26 \%$ & $43 \%$ & $17 \%$ & $7 \%$ \\
\hline Me sinto inseguro diante do ensino remoto & $28 \%$ & $47 \%$ & $10 \%$ & $8 \%$ & $7 \%$ \\
\hline $\begin{array}{l}\text { Minha maior dificuldade ao EaD, e consequentemente no ensino remoto, } \\
\text { se deu pela falta de uma internet segura }\end{array}$ & $17 \%$ & $27 \%$ & $26 \%$ & $23 \%$ & $7 \%$ \\
\hline $\begin{array}{l}\text { Nesse período a IES dispôs de um time de TICs que permitiu alcançar } \\
\text { soluções frente as demandas da comunidade acadêmica e, } \\
\text { consequentemente ao ensino remoto }\end{array}$ & $10 \%$ & $14 \%$ & $26 \%$ & $33 \%$ & $17 \%$ \\
\hline
\end{tabular}

Fonte: Dados da pesquisa

A pandemia interrompeu as atividades presencial por exigência do isolamento social, na tentativa de reduzir a contaminação, muitas atividades foram paralisadas ou interrompidas e dentre elas as práticas acadêmicas presenciais. A esta afirmativa os respondentes foram maioria quando afirmaram em $91 \%$ que as práticas acadêmicas não foram interrompidas, mas realinhadas para modalidade remota.

O confinamento e a quarentena, por circunstâncias imperativas, têm trazido à tona formas de comunicação política provavelmente mais condizentes com o século XXI. Também estão surgindo mecanismos de governança não presenciais com grande potencial para se tornarem fórmulas de gestão permanentes, muito mais ágeis e eficientes, graças à tecnologia. (UNESCO, 2020).

Constatou-se que 78\% dos respondentes afirmaram que foi sim um grande desafio, uma vez ser pela primeira vez que estava se deparando de forma integral o ensino a distância, através da modalidade remota. $73 \%$ dos respondentes afirmam já terem experimentado o 
ensino a distância. O que poderia sinalizar que essa familiaridade promoveria uma maior aceitação ao migrarem para o ensino remoto.

O setor da educação precisa se unir para postular um futuro em que os alunos possam receber suporte digital, que proporcione qualidade acadêmica e os padrões curriculares (WARGO; D’ALENE, 2020; CRAWFORD et al., 2020), o que se pode observar pela resposta é que a instituição já postula a ideia com a inserção dos alunos, e professores com $20 \%$ de atividades a distância. O que promoveu de forma antecedente a experiência com o EaD (BRITO; FERASSO; ESTRELA, 2020; FERNANDES; HENN; KIST, 2020).

Quanto a conhecer que as IES dispõem de ferramentas, como espações destinado ao desenvolvimento de mecanismos digitais como sala invertida, lousa digital e salas de metodologias ativas, 64\% dizem desconhecer esses espaços, o que se revela preocupante pois se a instituição tem esses espaços estão sendo mal usados ou então mal informados, a comunidade acadêmica.

No que diz respeito ao ensino, as instituições buscaram nas estratégias de atividades educacionais remotas, uma alternativa para manter seus alunos em atividade, minimizando as consequências que as políticas de isolamento social poderiam acarretar nas atividades acadêmicas (SPALDING et.al., 2020). Além disso, essas tecnologias colaboram para a aproximação dos professores com seus alunos, no sentido de que o ensino a distância, ou remoto podem se tornar uma extensão das aulas, cooperando para que os professores possam dar retornos mais imediatos às atividades de ensino solicitadas aos seus alunos (RIBEIRO, CORRÊA, 2021), sendo determinante para bons resultados a as instituições disponibilizem ferramentas inovadoras, que estimulem e contribuam para o desenvolvimento das práticas remotas (BARBOSA; VIEGAS; BATISTA, 2020).

A essa afirmativa somente $4 \%$ dos docentes responderam que sentiram dificuldades ou tiveram resistência ao modelo de ensino remoto, o que evidencia que os professores endossaram e entenderam os motivos de dar continuidade ao processo de ensino aprendizagem (MALAN, 2020), que passou a ser adotada a partir do isolamento social pelas IES objeto de estudo. Vasconcelos e Oliveira (2017), afirmam que o professor, diante dos desafios propostos na atualidade e, em especial, na educação, frente a crescente gama de informações, necessita redimensionar as práticas pedagógicas, pois o conhecimento e a informação não são exclusivos, uma vez esse conhecimento estar acessível a todos em sua plenitude. 
Ribeiro e Corrêa (2021) corroboram com esta afirmação, pois, identificaram que os docentes não tiveram dificuldade de migrar do modelo tradicional da educação para o modelo remoto, o que permite dizer que esse desafio faz parte da rotina dos mesmos uma vez que os alunos da atualidade estão com informações à disposição via internet, e muitas vezes com o conhecimento em estado da arte, o que promove um desafio para os docentes em lidar com as salas de aula na modalidade presencial ou remota.

No caso da resistência dos discente $64 \%$ das respostas ficaram entre moderada e total correspondência ao enfrentar a modalidade remota, confirmando resistência na implementação do ensino remoto. O que evidencia um fato interessante uma vez serem eles os alunos que estariam mais aficionados a novas tecnologia, portanto ao enfrentamento do ensino remoto mais receptivo (HE et al., 2020).

Instituições de Ensino Superior de todo o mundo foram afetadas pela pandemia da COVID-19, (GUSSO et.al., 2020; MARKOWSKA-MANISTA; ZAKRZEWSKAOLĘDZKA, 2020) e implementar o ensino remoto foi a saída encontrada por algumas instituições privadas e públicas (HE et al., 2020). Ainda existe uma enorme lacuna digital entre os países e dentro de cada um deles, tanto que a adoção do e-learning como forma de garantir a continuidade pedagógica foi rejeitada por várias organizações estudantis em diferentes países africanos, por exemplo (UNESCO, 2020).

Uma ação mais centrada no desenvolvimento das competências e da autonomia do estudante já era uma realidade antes e agora é uma necessidade (CASTIONI; MELO, 2020), uma vez os alunos conforme o resultado do estudo ainda tem resistências ao ensino remoto. $\mathrm{E}$ o mundo contemporâneo modelado por tecnologias e inovação cada vez mais irá exigir egressos com conhecimento e que adote as novas tecnologias de forma integral e abrangente.

Ao se tratar dos mecanismos de avaliação adotado como provas, em torno de $50 \%$ dos respondentes afirmam que não tiveram dificuldades com as provas remota. O processo de avaliação do ensino remoto difere de avaliações presencial, e a adaptação a essa modalidade de provas on line se mostrou mais lenta. As provas se constituem de forma oral, seminários, questionários elaborados em forms, com tempo definido para resposta. E as metodologias implementadas diferem de instituições, que tentaram se adequar da melhor forma possível.

Foi constatado que $90 \%$ responderam com moderada, muita e total correspondência quanto a inclusão do discente nas aulas de forma on-line, o que pode ser considerado como muito exitoso a oferta dessa modalidade de ensino, nas IES objeto de estudo. O uso da tecnologia como ferramenta de 
ensino pode auxiliar no processo educacional e, por consequência, na rotina de todos os atores envolvidos nesse processo - alunos, professores e gestores.

Neste período atual, a utilização dessas ferramentas tem sido fundamental no ensino (SPALDING et. al., 2020). Sendo evidente que a comunidade acadêmica integrada favorece a implantação e manutenção do ensino remoto. É necessário que alunos, professores, profissionais de suporte e todos os demais envolvidos estejam preparados para uma mudança de paradigma, com capacidade de inovação, resolução e adaptação aos novos problemas inerentes a qualquer novo processo a ser implementado. Assim como o estabelecimento de práticas e iniciativas para promover melhorias (SPALDING et.al., 2020).

Verificou-se que, para $52 \%$ dos respondentes o ensino presencial ainda proporciona o processo didático pedagógico melhor. O que pode ocorrer em virtude da novidade e da falta de familiaridade dos alunos e docentes no processo. As formas tradicionais de educação à distância, ou seja, aquelas em que o professor continua a dar uma aula comum que é transmitida ao vivo e pode ser vista posteriormente, parecem ser as mais apreciadas pelos estudantes, porque reproduzem melhor a dinâmica a que estão acostumados (UNESCO, 2020).

Iniciativas que tentam alterar radicalmente as regras de funcionamento e exigem que os estudantes saiam de sua zona de conforto sem nenhum treinamento prévio são menos apreciadas porque, por razões bem diferentes, os universitários tendem a ser mais conservadores do que se poderia pensar ou menos dispostos a mudanças (WATTS, 2016). O fato de que os estudantes terem se matriculado em ensino presencial, e de forma tempestiva terem que se adaptar ao remoto, pode levar a esse reconhecimento de que o processo didático pedagógico remoto não ser melhor que o presencial.

Segundo $73 \%$ dos respondentes, a uma concordância do grande impacto que foi sair do modelo presencial para o EaD (FERNANDES; HENN; KIST, 2020). Deve-se esse impacto pelo fato de que alunos e professores estavam adaptados ao modelo presencial. Se as IES tivessem planejado adaptar a oferta das atividades presenciais para algo mais próximo do que é realizado na modalidade $\mathrm{EaD}$ (CAMACHO et al., 2020), ainda com todas as possíveis limitações que isso implicaria, seria possível sustentar a ideia de manutenção, em algum grau, da qualidade do ensino (GUSSO et. al., 2020).

As IES objeto do estudo já faziam uso dos $20 \%$ em EaD, e mesmo assim a mudança causou impacto. O estudo de Spalding et. al. (2020), apresentou resultados que mostraram 
engajamento e desempenho promissores dos estudantes, na adaptação para o ensino remoto. Para UNESCO (2020), parece não ter sido recebida de forma positiva, e essa insatisfação decorre dos alunos não terem se inscrito para educação à distância. Esses contrapontos evidenciam que da mesma forma que estudos corroboram o engajamento e adaptação de alunos na modalidade remota, o fato de não ter sido a primeira opção o ensino remoto, esse fato exerce a insatisfação identificada.

Existe uma concordância em $83 \%$ de que o fato de ter familiaridade e domínio com tecnologia, tornou confortável a mudança do ensino presencial para remoto. O ensino à distância, diferentemente das atividades remotas emergenciais (BARBOSA; VIEGAS; BATISTA, 2020), é uma modalidade de ensino bem consolidada (JOYE; MOREIRA; ROCHA 2020). O que pode ser comprovado pela IES que já trabalhavam com a modalidade a distância. A modalidade a distância necessita além de docentes, e tutores, produção de material e domínio de ferramentas que ajudem a rotina de aplicação de conteúdos e equipamentos que deem acesso a internet.

Além da produção de conteúdos digitais por professores, há necessidade de profissionais que colaboram na gestão da aprendizagem, de design educacional, como profissional que contribui no planejamento, além de um forte investimento tecnológico na estrutura física e na capacitação dos atores envolvidos (SPALDING et al., 2020). Existe um envolvimento do grupo de profissionais que fomenta o uso das novas tecnologias, sendo imprescindível investimentos financeiros, que inibam problemas de ordem técnica, isso proverá as instituições de maior segurança no processo, gerando tranquilidade a comunidade acadêmica.

Para 33\% dos respondentes não foi sentido a falta dos encontros presenciais, o que evidencia que apesar dos encontros serem virtuais eles atenderam em parte a necessidade de convívio social entre a comunidade acadêmica. As aulas teóricas, que eram tradicionalmente ministradas presencialmente em encontros semanais ao longo do ano, atualmente foram substituídas por videoaulas gravadas dos assuntos programados no cronograma de atividades proposto no início do ano letivo (SPALDING et. al., 2020). Muitos docentes inovaram tornando os encontros remotos interessantes e atrativos, minimizando a necessidades ou falta dos momentos presenciais.

A insegurança perante o ensino remoto foi pouco sentida pelos respondentes, somente $25 \%$ deles relatam esse sentimento de insegurança. O que pode ter ocorrido é que pelo fato de já estarem familiarizados com o ensino a distância pois a instituição já havia implantado $20 \%$ do $\mathrm{EaD}$, conforme a legislação vigente, possível para complementar o ensino presencial. Observou-se que $44 \%$ dos respondentes acreditam que se prejudicaram pela falta de internet, 
ou perda de acesso durante as aulas remotas. O fato é que uma internet instável prejudica não somente o alunado, mas também o professor que fica impedido de ministrar suas aulas.

Contemplou-se que para $76 \%$ dos respondentes a IES dispôs de pessoas capazes de serem resolutivas frente as demandas da comunidade acadêmica, o que proveu o ensino remoto de qualidade. As respostas que as instituições de ensino superior estão construindo às demandas sociais e de ciência, tecnologia e inovação frente à pandemia da COVID-19, evidencia a força institucional destas.

A intensidade e a amplitude de tais respostas, com relação à investigação e às ações em tantas áreas do conhecimento; como a saúde pública, comunicação, construção de redes de solidariedade em diversas áreas, estudos urbanos e de produção de mercadorias, transporte e circulação; são exemplos do que as Universidades estão realizando, incitadas pelas múltiplas crises causadas pela pandemia. (CASTIONI; MELO, 2020). É difícil prever o impacto que a mudança nas modalidades de ensino e aprendizagem pode ter, no médio e no longo prazo, sobre os estudantes (UNESCO, 2020; MALAN, 2020), mas o que é certo é que ainda não se sabe quando as pessoas estarão vacinadas o suficiente para garantir um retorno à normalidade presencial.

Em princípio, o ensino presencial está sendo reproduzidas por meios tecnológicos, e o retorno as salas de aula, quando ocorrer, terá como suporte as ferramentas e a expertise experimentada e desenvolvida pelas instituições, porque o retorno à sala de aula será experimentado como um retorno à uma nova normalidade. Por outro lado, também é preciso ter em mente que a experiência, em alguns casos, resultará em muitas dúvidas sobre a necessidade de se retornar completamente à sala de aula, sem se aproveitar plenamente as oportunidades oferecidas pelas tecnologia (UNESCO, 2020).

As instituições superiores do mundo estão enfrentando a pandemia da COVID-19 com respostas rápidas no âmbito do ensino, da pesquisa e do diálogo internacional em sintonia com as demandas da sociedade. (CASTIONI; MELO, 2020). Cada vez mais as instituições estarão superando as dificuldades impostas por condições contingências e terão respostas mais imediatas para esse tipo de demanda.

\section{CONSIDERAÇÕES FINAIS}

O objetivo deste estudo foi investigar a influência do ensino remoto na educação superior nas Instituições de Ensino Superior Privadas (IESsP) de um Grupo Educacional do 
Brasil (GEB) localizadas no Piauí. Foi relatado pelos respondentes que a mudança do ensino presencial para o remoto, não foi tão impactante pelo fato de já terem sido implantado nas IESs objeto de estudo os $20 \%$ do $\mathrm{EaD}$ o que possibilitou a familiaridade dos respondentes no ensino remoto. Pode-se perceber que os respondentes reconhecem que o ensino remoto ainda não substitui o presencial em aprendizado, mas que se adaptaram bem a modalidade.

Apesar dos impactos da pandemia, que ocasionaram o isolamento social, os resultados evidenciam que as IES ligadas ao grupo educacional objeto do estudo, não tiveram interrupção das aulas, que ocorreram de forma remota. Os principais resultados evidenciam que as instituições respondentes, possuem ferramentas tecnológicas que facilitam o desenvolvimento das aulas remotas, usam metodologias ativas e os docentes por estarem familiarizados a modalidade $\mathrm{EaD}$ não tiveram muitas dificuldades em migrar para o sistema remoto, e muitos dos respondentes se sentiram desafiados em participar de atividades na modalidade ensino remoto.

Concluiu-se que as instituições estudadas tiveram menos impactos no processo de mudança do ensino presencial para o remoto, na visão dos alunos e professores respondentes. Neste momento a forma ideal por ser a mais segura de dar continuidade aos estudos em todas os níveis da educação seria $\mathrm{EaD}$, uma vez que não interrompe o processo educacional. A falta de referências a crises semelhantes, como essa que levaram ao isolamento social, no passado, torna difícil prever o que pode acontecer em um futuro em curto ou médio prazo, em relação ao ensino presencial. Para a UNESCO (2020), os efeitos presentes estão sendo documentados, e deixarão sua marca nos diferentes envolvidos, instituições, alunos, professores e sociedade em geral, no médio e no longo prazo. Portanto estudos como este podem esclarecer e relatar como o ensino remoto está promovendo a inclusão nos tempos de isolamento social.

A principal contribuição do estudo é evidenciar resultados em estado da arte sobre como IESs que conseguiram tempestivamente evoluírem para o ensino remoto, podendo ser útil para outras instituições o modelo adotado por estas. Como limitação, temos a devolutiva dos respondentes, que apesar de ter sido enviado a um número representativo de docentes e discente, as devolutivas foram menores que o esperado. Como sugestões para futuros estudos, a possibilidade de cruzar informações acerca do aproveitamento do referido estudo de forma remota, em instituições públicas e privadas; bem como estudar IESs sobre as evoluções tecnológicas e TICs adotados por elas, nesse período de implementação do ensino remoto. 


\section{REFERÊNCIAS}

BARBOSA, A. M.; VIEGAS, M. A. S.; BATISTA, R. L. N. F. F. Aulas presenciais em tempos de pandemia: relatos de experiências de professores do nível superior sobre as aulas remotas. Revista Augustus, v. 25, n. 51, p. 255-280, 2020

BEZERRA, I. M. P. State of the art of nursing education and the challenges to use remote technologies in the time of corona virus pandemic. Journal of Human Growth and Development, v. 30, n. 1, p. 141-147, 2020.

BRITO, C. E.; FERASSO, M.; ESTRELA, S. M. P. P. L. A Gestão dos Cursos EAD em Moçambique. Revista Internacional de Educação Superior, v. 6, p. 1-24, 2020.

CAMACHO, A. C. L. F.; FULY, P. dos S. C.; SANTOS, M. L. S. C. dos; MENEZES, H. F. de. Alunos em vulnerabilidade social em disciplinas de educação à distância em tempos de COVID-19. Research, Society and Development, v. 9, n. 7, p. 1-12, 2020.

CASSUNDÉ, F. R. de S. A.; MENDONÇA, J. R. C. de; BARBOSA, M. A. C. A influência das condições institucionais no desenvolvimento de competências eletrônicas dos professores para o ensino na EAD: proposição de um modelo analítico. Avaliação: Revista da Avaliação da Educação Superior (Campinas), v. 22, n. 2, p. 469-493, 2017.

CASTIONI, R.; MELO, A.A.S. Universidades do Brasil, da Espanha e da Itália na pandemia da Covid-19 numa perspectiva comparada. Revista Brasileira de Educação Comparada, v. 2, p. 1-16, 2020.

CRAWFORD, J.; HENDERSON, K. B.; RODOLPH, J.; MALKAWI, B.; GLOWATZ, M.; BURTON, R.; MAGNI, P. A.; LAM, S. COVID-19: 20 countries' higher education intra-period digital pedagogy responses. Journal of Applied Learning \& Teaching, v. 3, n. 1, p. 1-20, 2020.

DHAWAN, S. Online learning: a panacea in the time of COVID-19 crisis. 2 Journal of Educational Technology Systems, p. 1-18, 2020.

FERNANDES, S. M.; HENN, L. G.; KIST, L. B. O ensino a distância no Brasil: alguns apontamentos. Research, Society and Development, v. 9, n. 1, p. 1-24, 2020.

GARCIA FILHO, C.; VIEIRA, L. J. E. de S.; SILVA, R. M. da. Buscas na internet sobre medidas de enfrentamento à COVID-19 no Brasil: descrição de pesquisas realizadas nos primeiros 100 dias de 2020. Epidemiologia e Serviços de Saúde, v. 29, p. 1-6, 2020.

GONÇALVES, P. P.; SILVA, C. N. da. Educação a distância e formação profissional do/da assistente social: elementos para o debate. Revista Katálysis, v. 23, n. 1, p. 90-100, 2020.

GOUVÊA, M. A.; ONUSIC, L. M.; MANTOVANI, D. M. N. Qualidade e lealdade ao curso no ensino superior. Revista de Administração da UFSM, v. 9, n. 1, p. 26-45, 2016.

GUSSO, H. L.; ARCHER, A.; LUIZ, F. B.; SAHÃO, F. T.; LUCA, G. G. de; HENKLAIN, M. H. O.; PANOSSO, M. G.; KIENEN, N.; BELTRAMELLO, O.; GONÇALVES, V. M. 
Ensino superior em tempos de pandemia: diretrizes à gestão universitária. Educação \& Sociedade, v. 41, p. 1-26, 2020.

HE, S.; LAI, D.; MOTT, S.; LITTLE, A.; GROCK, A.; HAAS, M. R.; CHAN, T. M. Remote e-work and distance learning for academic medicine: best practices and opportunities for the Future. Journal of Graduate Medical Education, p. 256-263, 2020

JOYE, C. R.; MOREIRA, M. M.; ROCHA, S. S. D. Distance education or emergency remote educational activity: in search of the missing link of school education in times of COVID-19. Research, Society and Development, v. 9, n. 7, p. 1-29, 2020.

KUWAHARA, K.; KURODA, A.; FUKUDA, Y. COVID-19: Active measures to support community-dwelling older adults. Travel Medicine and Infectious Disease, 2020.

MACIEL, C. E.; CUNHA JÚNIOR, M.; LIMA, T. da S. A produção científica sobre permanência e evasão na educação superior no Brasil. Educação e Pesquisa, v. 45, p. 1-20, 2019.

MALAN, M. Engaging students in a fully online accounting degree: an action research study. Accounting Education, p. 1-19, 2020.

MANCHEIN, C. et al. Strong correlations between power-law growth of COVID-19 in four continents and the inefficiency of soft quarantine strategies. arXiv:2004.00044, v. 2, 2020.

MARASCA, A. R.; YATES, D. B.; SCHNEIDER, A. M. de A.; FEIJÓ, L. P.; BANDEIRA, D. R. Avaliação psicológica online: considerações a partir da pandemia do novo coronavírus (COVID-19) para a prática e o ensino no contexto a distância. Estudos de Psicologia

(Campinas), v. 37, p. 1-11, 2020.

MARKOWSKA-MANISTA, U.; ZAKRZEWSKA-OLĘDZKA, D. Family with children in times of pandemic - what, where, how? dilemmas of adult-imposed prohibitions and orders. Society Register, v. 4, n. 3, p. 89-110, 2020.

MARTINS, L. M. de; RIBEIRO, J. L. D. Proposta de um modelo de avaliação do nível de engajamento do estudante da modalidade a distância. Avaliação: Revista da Avaliação da Educação Superior (Campinas), v. 24, n. 1, p. 8-25, 2019.

PIMENTA, A. M.; ROSSO, S. D.; SOUSA, C. A. L. de. A reprodução educacional renovada: dualidade intrainstitucional no programa Universidade Aberta do Brasil. Educação e Pesquisa, v. 45, p. 1-14, 2019.

PÉRICO, F. G.; GONÇALVES, R. B. Intercâmbio acadêmico: as dificuldades de adaptação e de readaptação. Educação e Pesquisa, v. 44, p. 1-21, 2018.

REYES JÚNIOR, E.; REIS, A. L. N.; COSTA, V. F. de S.; SANTOS, Y. A. dos. Relações interpessoais e sua influência na satisfação dos acadêmicos. Revista de Gestão e Secretariado, v. 9, n. 3, p. 206-228, 2018. 
RIBEIRO, H. C. M. O envolvimento da governança corporativa, sob a ótica da teoria dos stakeholders, na gestão e no controle das entidades esportivas. Tese (Doutorado em Administração), UNINOVE, São Paulo, 2014.

RIBEIRO, H. C. M.; CORRÊA, R. Estratégias de ensino superior praticadas nas instituições superior privada de um grupo educacional do Brasil frente a pandemia do COVID-19.

Revista Gestão Organizacional, v. 4, n. 1, p. 333-355, 2021.

RIBEIRO, M. F.; SARAIVA, V.; PEREIRA, P.; RIBEIRO, C. Escala de motivação académica: validação no ensino superior público português. Revista de Administração Contemporânea, v. 23, n. 3, p. 288-310, 2019.

SANTOS, A. G.; PEREIRA, R. da S.; PALMISANO, A.; LUCAS, E. C. Instituições de ensino superior de capital aberto atuantes no Brasil: análise sob a ótica da governança e da responsabilidade socioambiental. Gestão \& Regionalidade, v. 36, n. 108, p. 181-201, 2020.

SILVA, A. G.; MIRANDA, D. M.; DIAZ, A. P.; TELES, A. L. S.; MALLOY-DINIZ, L. F.; PALHA, A. P. Mental health: why it still matters in the midst of a pandemic. Brazilian Journal of Psychiatry, v. 42, n. 3, p. 229-231, 2020.

SILVEIRA, S. R.; BERTOLINI, C.; PARREIRA, F. J.; CUNHA, G. B. da; BIGOLIN, N. M. $O$ Papel dos licenciados em computação no apoio ao ensino remoto em tempos de isolamento social devido à pandemia da COVID-19. Série Educar - Volume 40 - Prática Docente, 2020.

SOUZA, C J. de; GUERRA, T. R. B.; CARVALHO, D. da. S.; JESUS, R. V. L. de; COSTA, L. H. O. da; ISSOBE, M. K.; VIEIRA, H. L. de S.; SANTOS, D. A. dos; ZAMBA, C. F. dos S. As interfaces da (re) invenção do ensino na graduação em enfermagem em tempo de COVID-19. Research, Society and Development, v. 9, n. 7, p. 1-19, 2020.

SPALDING, RAUEN, C.; VASCONCELLOS, L. M. R. de; VEGIAN, M. R. da C.; MIRANDA, K. C.; BRESSANE, A.; SALGADO, M. A. C. Desafios e possibilidades para o ensino superior: uma experiência brasileira em tempos de COVID-19. Research, Society and Development, v. 9, n. 8, p. 1-23, 2020.

UNESCO - Organização das Nações Unidas para a Educação, a Ciência e a Cultura.

Consequências adversas do fechamento das escolas. Disponível em:

https://pt.unesco.org/covid19/educationresponse/consequences. Acesso em 01 jan. 2021.

UNESCO - Organização das Nações Unidas para a Educação, a Ciência e a Cultura. COVID19 y educación superior: de los efectos inmediatos al día después; análisis de impactos, respuestas políticas y recomendaciones. Publicado em 2020 pela Organização das Nações Unidas para a Educação, a Ciência e a Cultura (UNESCO) e pelo Instituto Internacional para a Educação Superior na América Latina e Caribe (UNESCO-IESALC. Publicado em 2020 pela Organização das Nações Unidas para a Educação, a Ciência e a Cultura, 7, place de Fontenoy, 75352 Paris 07 SP, França, pelo Instituto Internacional para a 
Educação Superior na América Latina e Caribe e pela Representação da UNESCO no Brasil. Disponivel em: (http://creativecommons.org/licenses/by-sa/3.0/igo/). Acesso em: 01 jan,2021.

VALENTI, V. E.; MENEZES, P. de L.; DE ABREU, A. C. G.; VIEIRA, G. N. A.; GARNER, D. M. Medidas de distanciamento social podem ter reduzido as mortes estimadas relacionadas à COVID-19 no Brasil. J Hum Growth, v. 30, n. 2, p. 164-169, 2020.

VASCONCELOS, C. A.; OLIVEIRA, E. V. TIC no ensino e na formação de professores: reflexões a partir da prática docente. Revista Brasileira de Ensino Superior, v. 3, n. 1, p. 112-132, 2017.

VOLPATTO, D. T.; RESENDE, A. C. M.; ANJOS, L. dos; SILVA, J. V. O.; DIAS, C. M.; ALMEIDA, R. C.; MALTA, S. M. C. Avaliação de estratégias de relaxamento do distanciamento social para o Brasil e estado do Rio de Janeiro. Disponível em: < file://C:/Users/hcmri/Downloads/595-Preprint\%20Text-872-1-10-20200528.pdf>. Acesso em: jul/2020.

WARGO, E. S.; D'ALENE, C. Intertwined higher education places and spaces. Journal for the Study of Postsecondary and Tertiary Education, v. 5, p. 79-84, 2020.

WATTS, L. Synchronous and asynchronous communication in distance learning: a review of the literature. Quarterly Review of Distance Education, v. 17, n. 1, p. 23-32, 2016.

YAMANAKA, T. B.; CAPPELLOZZA, A. Explorando a influência integrada do Estímulo Docente sobre a intenção de uso das bibliotecas virtuais por estudantes de cursos à distância $\mathrm{e}$ presenciais no Brasil. Investigación bibliotecológica, v. 32, n. 75, p. 19-45, 2018. 